\title{
Empowerment: Trait Relatedness
}

Joel E. Rodgers, Nova Southeastern University, USA

Thomas E. Griffin, Nova Southeastern University, USA

\begin{abstract}
The purpose of this study was to determine whether the extent that variances in the level of empowerment can be influenced by the willingness of supervisor to empower, the willingness of subordinates to be empowered and the subordinators' age. The results indicate that there is a positive relationship between subordinates' empowerment level and the subordinates' willingness to be empowered; but there is no significant relationship between subordinates' empowerment level and the supervisors' willingness to empower.
\end{abstract}

Keywords: empowerment, willingness, age

\section{INTRODUCTION}

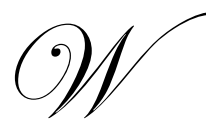

ith the recent shift of major organizations to emulate the very successful corporations that employ Six Sigma and other participative management platforms middle managers have become problem solvers. Organizations require middle managers to act in an empowered fashion. A major debate exists over the ability of organizations efforts to empower middle managers. Many leaders falsely think they are empowering subordinates when they merely involve them in decisions. Empowerment is the sharing of a leader's power by a subordinate. The primary purpose of this study was to determine if organizations could empower their middle managers.

In this study, the researcher examined the level of empowerment of middle managers of a large corporate entity. The researcher measured the level of empowerment of middle managers by asking them questions to determine the latitude that they employed in the performance of their job. The researcher focused on how much direction middle managers needed to make decisions and perform task within the scope of their job as well as beyond the scope of their job. In addition, the researcher focused on the sense of urgency that the middle manager placed on reporting resulting actions.

\section{LITERATURE REVIEW}

Empowerment has been a "buzz" word for the last quarter century. Hersey and Blanchard conceptual framework for the examination of the construct "empowerment" was a first step. (Hersey \& Blanchard, Life Cycle Theory of Leadership, 1969) (Dixon \& Dogan, 2003). Empowerment is defined as the sharing of power which is manifested as the level of freedom a subordinate has to make decisions. This freedom is given to the subordinate by his or her supervisor. However, unless an employee has a willingness to be empowered and a sufficient level of maturity, he or she will not act in an empowered fashion. More recent research on transformational leadership discusses the role of leadership behavior and subordinate behavior (Ozaralli, 2003). Recent research state the need for novel approaches to leadership and followership to deal with organizational designs that handle environmental complexities (Bligh, Pearche, \& Kohles, 2006). Yate (1991) proposed that a subordinate's level of empowerment is dominated by the level of delegation of power offered by the leader. His research determined the level of freedom that a subordinate has to act was significant (Walumbwa, Orwa, Wang, \& Lawler, 2005).

Conger and Kanugo (1988) concluded that empowerment of subordinates may prove to be an important path to organizational change. They found that empowered individuals have higher expectations than they had prior to empowerment. Zimmerman (1990) determined that participation is necessary to achieve empowerment but participation alone will not yield empowerment. Hollander and Offerman (1990) described the delegation of decision making responsibility as situational. They found that delegation, unlike participation, distributes power 
selectively rather than equally. Leaders that delegate consider the ability and the responsibility of the follower for the task. Leana (1987) determined that managers do distinguish between delegation and participation. Leana found that managers determine the level of delegation versus participation on a situational basis; based on the specific decision rather than their overall trust in a subordinate. Vroom (1976) found that no manager used the same decision process for all decisions. He found that the subordinate is the important element in the choice of leadership style and technique. Hersey and Blanchard's SLT focuses on the interaction of leader flexibility and the dual construct "maturity" or "readiness" of the subordinate. This interaction results in a subordinate being situational empowered. Subordinates will make decisions and perform tasks in accordance with their level of empowerment. Spreitzer (1995) determined that empowerment is a continuous variable. People can be viewed as more or less empowered. Spreitzer's research also found empowerment to be specific to the work domain.

In this study, the researcher examined and measured the empowerment levels of middle managers of a Fortune 500 entity. The study focused on the extent that variances in the studied middle manager's empowerment level can be explained by the variables historically used by researchers to study situational leadership. The observed variances in empowerment level have been correlated to the factors most often used to ascertain maturity and/or readiness. The factors are willingness to be empowered and subordinate's perspective of his or her supervisor" willingness to empower.

\section{RESEARCH QUESTIONS AND HYPOTHESES}

The first research question asked whether variations in the level of empowerment can be explained by the variables commonly used by researchers in their attempts to validate the Hersey and Blanchard Situational Theory.

Leana (1987) and Yate (1991) focus on the importance of determining the willingness of a subordinate to be empowered and the willingness of the leader to empower the subordinate.

Many researchers have used elapsed time to quantify maturity.

\section{Research Question 1}

Can variations in the level of empowerment of middle managers be explained by one or more of the variables: willingness to be empowered, willingness of leader to empower, or age?

\section{Hypothesis 1}

Null: Across middle managers, the level of empowerment demonstrated by a subordinate will be negatively related or unrelated to the subordinate" willingness to be empowered.

Alternative: Across middle managers, the level of empowerment demonstrated by a subordinate will be positively related to the subordinate's willingness to be empowered.

The subordinate's willingness to be empowered was determined for each middle manager. The relationship between willingness to be empowered and resulting empowerment was determined. Analysis of Variance (ANOVA) was used to determine the importance of the independent variable, willingness to be empowered.

\section{Hypothesis 2}

Null: Across middle managers, the level of empowerment demonstrated by a subordinate will be negatively related or unrelated to the supervisor's willingness to empower, as viewed by the subordinate.

The subordinate's understanding of his or her supervisor's willingness to empower was determined for each middle manager. The relationship between perceived willingness to empower and empowerment was determined. Analysis of Variance (ANOVA) was used to determine the importance of the independent variable willingness of leader to empower, in determining empowerment. 


\section{Hypothesis 3}

Null: Across middle managers, the level of empowerment demonstrated by a subordinate will be unrelated to the age of the subordinate.

Alternative: Across middle managers, the level of empowerment demonstrated by a subordinate will be related to the age of the subordinate.

The middle manager's age was reflected by his or her selection of a mutually exclusive age grouping. The mean level of empowerment for each age grouping was compared to the mean level of empowerment of the sample. Analysis of Variance (ANOVA) was used to determine the importance of the independent variable age, in determining empowerment.

The variables and their relationships are demonstrated in Table 1.

Table 1 Variables and their relationships

\begin{tabular}{|l|c|c|}
\hline \multicolumn{1}{|c|}{ Variable } & Variables & Type \\
\hline X1 - Empowerment & Relationship & Metric \\
\hline Y1 - Employee Willingness & Dependent & Non metric \\
\hline Y2 - Supervisor Willingness & Independent & Non metric \\
\hline Y3 - Age & Independent & Non metric \\
\hline Y3a - Age <1 yr. & & Non metric \\
\hline Y3b - Age 30-50 & Independent & Non metric \\
\hline Y3c - Age 51-65 & Independent & Non metric \\
\hline Y3d - Age $>65$ & Independent & \\
\hline
\end{tabular}

\section{Measuring Empowerment X1}

The study of the literature leads to the conclusion that the best way to measure levels of empowerment is to query subordinates as to the level of decisions that they are making and the degree of autonomy that they perceive that they have to make them. In this study, the researcher asked middle managers five questions to determine their level of empowerment. The questions were weighted to place more significance on the employee's empowerment level in his or her current work assignment. The questions asked were as follows:

A. In making decisions within the scope of my job, I

(a) Wait until told

(b) Ask what to do

(c) Recommend then take resulting action

(d) Act then advise at once

(e) Act then report routinely.

B. When performing tasks within the scope of my job, I

(a) Wait until told

(b) Ask what to do

(c) Recommend then take resulting action

(d) Act then advise at once

(e) Acct then report routinely

C. In the normal course of business I make decisions that are often made by my supervisors $\%$ of the time. 
D. When performing tasks normally made by my supervisor, I
(a) Wait until told
(b) Ask what to do
(c) Recommend then take resulting action
(d) Act then advise at once
(e) Act then report routinely

E. In making decisions normally made by my supervisor, I:
(a) Wait until told
(b) Ask what to do
(c) Recommend and then take resulting action
(d) Act then advise at once
(e) Act then report routinely

\section{Measuring Supervisor's Willingness to Empower Y2}

Many supervisors believe that they are empowering their subordinates by merely involving them in the process of decision making. To be empowered a subordinate must believe that his or her supervisor is willing to allow the subordinate employee to use some of his or her supervisor's power to make decisions. Two questions were asked of the subordinate to determine the subordinate's view as to the willingness of his or her supervisor to empower. The question dealing with delegation was more heavily weighted. The questions asked were:

A. My supervisor delegates authority to me.
(a) Almost always
(b) Usually
(c) Frequently
(d) Seldom
(e) Almost never

B. My supervisor encourages me to be innovative.

(a) Almost always

(b) Usually

(c) Frequently

(d) Seldom

(e) Almost never

\section{Measuring Age Y3}

Zimmerman (1990) concluded that age was not a significant modifier of the ability of a person to learn to be empowered. There is, however, a great deal of anecdotal evidence supporting the thesis that people are not to be trusted until they are at least 30 years old and that older managers are not risk takers. Additional anecdotal evidence suggests that managers that are past normal retirement age can and do take additional risks without putting their long term security in jeopardy. For this study respondents classified themselves as:
A. Under 30
B. $\quad 30$ to 50
C. 51 to 65
D. Over 65

Each mutually exclusive age grouping was treated as a separate independent variable. 


\section{RESEARCH DESIGN}

\section{Sample}

A study was conducted by sampling middle managers from a Fortune 500 Industrial Manufacturing firm employing in excess of 1000 people. To confirm that the employees were middle managers they were asked:

A. The levels between you and CEO

B. The levels between you and the first level of supervision.

The sample consisted of 113 middle level managers. The sample was obtained through the firm's Human Relations staff, as directed by their Vice President for Human Relations. Respondents were assured of data confidentiality.

\section{Research Instrument}

The original concept of measuring empowerment by determining an employee's method of performing tasks was developed in 1992 as a partial fulfillment of a Nova University course requirement.

The survey was modified for this study. Modifications included adding questions to determine how employees made and reported the results of decisions. To establish reliability, the revised questionnaire was given to 10 Nova Southeastern University, Phoenix Cluster DBA students. Each student was interviewed after completing the questionnaire. The result of the interviews included:

A. Removing diagram. Questions were expanded to include information previously obtained from the diagram.

B. Changing the measurement of organizational levels to identify middle managers.

C. Deleting question regarding how a middle manager performs tasks normally performed by subordinates.

The revised questionnaire was re-formatted t permit printing on one sheet of legal size paper. To confirm reliability, the questionnaire was given to 22 Nova Southeastern University Fort Lauderdale MBA students. The test confirmed the reliability of the questionnaire.

Validity was confirmed by using Chi Square tests. The tests compared the data sets obtained from two of the studied firm's Strategic Business Units surveyed to the total sample to determine goodness of fit. Please see the validity results for this study at table $2 \& 3$. Table 4 demonstrates the demographic characteristics of the respondents.

Table 2

Chi-Square Test: Validity

$\begin{aligned} & \text { Degrees of Freedom: } 2 \\
& \text { Critical Value }\end{aligned}$
\begin{tabular}{|c|c|c|c|c|c|c|}
\hline & $\mathbf{1 0}$ & $\mathbf{4 . 6 0 5}$ & $\mathbf{0 5}$ & $\mathbf{5 . 9 9 1}$ & \multicolumn{2}{|c|}{$\mathbf{4 0 . 1}$ to 50 } \\
\hline & & $\mathbf{0}$ to $\mathbf{3 5}$ & $\mathbf{3 5 . 1}$ to 40 & $\mathbf{\text { EXP }}$ & OBS & EXP \\
\hline SBU 1 & OBS & EXP & OBS & 9.8 & 13 & 13.8 \\
\hline SBU 2 & 4 & 4.8 & 11 & 9.5 & 13 & 13.2 \\
\hline
\end{tabular}

In this study, the researcher examined and measured the empowerment levels of middle managers of a Fortune 500 entity. The study focused on the extent that variances in the studied middle manager's empowerment level can be explained by the variables historically used by researchers to study situational leadership. The observed variances in empowerment level have been correlated to the factors most often used to ascertain maturity and/or readiness. The factors are willingness to be empowered and subordinate's perspective of his or her supervisor" willingness to empower. 
Table 3: Chi-Square Statistic

\begin{tabular}{|c|c|c|}
\hline OBS & EXP & CHI-SQ. STATISTIC \\
\hline 4 & 4.8 & .12 \\
\hline 11 & 9.8 & .15 \\
\hline 13 & 13.8 & .05 \\
\hline 3 & 4.6 & .56 \\
\hline 11 & 9.5 & .23 \\
\hline$\underline{13}$ & 13.2 & $\underline{.0}$ \\
\hline
\end{tabular}

Table 4

Demographic Characteristics of Respondents

\begin{tabular}{|c|c|c|}
\hline Gender & 92 Male & 21 Female \\
\hline Age & & 11 \\
\hline & Less than 30 & 71 \\
\hline & 30 to 50 & 29 \\
\hline Total & 51 to 65 & 2 \\
\hline
\end{tabular}

With the recent shift of major organizations to emulate the very successful corporations that employ Six Sigma and other participative management platforms middle managers have become problem solvers. Organizations require middle managers act in an empowered fashion. A major debate exists over the ability of organizations efforts to empower middle managers. Many leaders falsely think they are empowering subordinates when they merely involve them in decisions. Empowerment is the sharing of a leader's power by a subordinate.

The primary purpose of this study was to determine if organizations could empower their middle managers. The researcher examined the level of empowerment of middle managers of a large corporate entity. The purpose of the examination was to determine the extent that variances in the level of empowerment can be explained by the variables willingness to take the risks required to make a decision, willingness of supervisor to empower as viewed by the subordinate and age.

In this study, the researcher determined that a positive relationship does exist between the willingness of a subordinate to be empowered, a combination of willingness of the subordinate to be empowered and the age of the subordinate, to the resulting level of empowerment of the subordinate. The results of this study, however, determined that there is not a significant relationship between subordinate empowerment and the supervisor's willingness to empower as viewed by the subordinate. This supports the theory that organizations cannot empower employees unless the employee is willing to be empowered. The researcher measured the level of empowerment of middle managers by asking them questions to determine the latitude that they employed in the performance of their job. The researcher focused on how much direction middle managers needed to make decisions and perform task within the scope of their job as well as beyond the scope of their job. In addition, the researcher focused on the sense of urgency that the middle manager placed on reporting resulting actions.

\section{AUTHOR INFORMATION}

Joel E. Rodgers is an Adjunct Professor at Nova Southeastern University School of Business and Entrepreneurship. $\mathrm{He}$ is a retired Vice President of Allied Signal and former CEO of Baron Blakeslee Inc. He teaches master level courses in Leadership and Strategy.

Dr. Thomas Griffin is Professor of Decision Sciences at the H. Wayne Huizenga School of Business and Entrepreneurship at Nova Southeastern University. He teaches master lever and doctoral level courses including strategy, statistics, operation management and finance. 


\section{REFERENCES}

1. Bligh, M. C., Pearche, C. L., \& Kohles, J. C. The importance of self- and shared leadership in team based knowlege work: A meso-level model of leadership dynamics. Journal of Managerial Psychology, Vol. 21, No. 4, pp. 296-318, 2006.

2. Conger, J. \& Kanungo, R. The Empowerment Process: Integrating Theory and Practice. Academy of Management Review, V. 13. pp. 46-78, 1988.

3. Dixon, J., \& Dogan, R. A philosophical analysis of managemnt: improving praxis. Journal of Management Development, Vol. 22, No. 6, pp. 458-482, 2003.

4. Hersey, P., \& Blanchard, K. H. Life Cycle Theory of Leadership. Training and Development Journal, pp. 25-37, 1969.

5. Hersey, P., \& Blanchard, K. H. Management of Organizational Behavior. Englewood Cliffs: Prentice Hall, 1996.

6. Ozaralli, N. Effects of transformational leadership on empowerment and team effectiveness. Leadership and Organizational Development Journal, Vol. 24, Nol. 6, pp. 335-344, 2003.

7. Hollander, E.P., \& Offerman, L.R. Power and Leadership in Organizations. American Psychologist, Vol. 45, No. 2, pp. 179-189, 1990.

8. Leana, C.R. Power Relinquishment Versus Power Sharing: Theoretical Clarification and Empirical Comparison of Delegation and Participation. Journal of Applied Psychology. V. 72-2. pp. 228-233, 1987.

9. Spreitzer, G.M. Psychological Empowerment in the Workplace: Dimensions, Measurement, and Validation. Academy of Management Journal. V. 38-5. pp. 1442-1465, 1995.

10. Vroom, V. Can Leaders Learn to Lead? Organizational Dynamics. Winter, pp. 17-28, 1976.

11. Walumbwa, F. O., Orwa, B., Wang, P., \& Lawler, J. J. Transformational leadership, organizational commitment, and job satisfaction: A comparative study of Kenyan and U.S. financial firms. Human Resource Development Quarterly, Vol. 16, No. 2, 235-256, 2005.

12. Yate, M. Delegation, The key to Empowerment. Training Development Journal. Apr. pp. 23-24, 1991.

13. Zimmerman, M.A. Toward a Theory of Learned Hopefulness: A Structural Model Analysis of Participation and Empowerment. Journal of Research in Personality, Vol. 24. pp. 71-86, 1990. 
NOTES 